Rev. Inst. Flor . v. 27 n. 1 p. 31-39 jun. 2015

http://dx.doi.org/10.4322/rif.2015.003

ISSN impresso 0103-2674/on-line 2178-5031

\title{
VARIABILIDADE GENÉTICA EM PROGÊNIES DE Pinus caribea var. hondurensis AOS 21 ANOS DE IDADE ${ }^{1}$
}

\section{GENETIC VARIABILITY IN PROGENIES OF Pinus caribaea var. hondurensis AT 21 YEARS OF AGE}

\author{
Hugo Rodrigo MACEDO²; Miguel Luiz Menezes FREITAS ${ }^{3,4}$; \\ Osmar Vilas BOAS ${ }^{3}$; Alexandre Magno SEBBENN ${ }^{3}$
}

\begin{abstract}
RESUMO - Pinus caribaea var. hondurensis é uma das espécies do gênero Pinus mais plantadas nas regiões tropicais por apresentar ótima adaptação às condições de solo e clima, ter rápido crescimento, boa forma do tronco e madeira de boa qualidade. A espécie é utilizada principalmente para serraria e produção de celulose e papel. O objetivo deste estudo foi estimar parâmetros genéticos para caracteres de crescimento em um teste de progênies de polinização aberta de Pinus caribaea var. hondurensis em Assis, Estado de São Paulo. O teste foi instalado em maio de 1987, na Floresta Estadual de Assis, no delineamento experimental látice triplo $4 \times 5$, com 17 tratamentos (16 progênies e uma testemunha experimental), quatro repetições e parcelas de dez plantas em linha, no espaçamento de $3 \times 3 \mathrm{~m}$. Foram medidos os caracteres altura total de plantas - ALT e o diâmetro à altura do peito - DAP aos 21 anos de idade. A análise de variância detectou diferenças significativas a $5 \%$ de probabilidade entre progênies para a variável altura. O coeficiente de variação genético para altura de plantas foi de $18,4 \%$, e $9,2 \%$ para o DAP. A estimativa do coeficiente de herdabilidade para a média de progênies foi de 0,30 para a altura e 0,02 para o DAP, maiores do que as obtidas para herdabilidade dentro de progênies e em nível de plantas individuais. Para estabelecer um pomar de sementes por mudas, sugere-se adotar o caráter altura e uma intensidade de seleção de $6 \%$, o que corresponde a selecionar os 32 melhores indivíduos. Isso resultou em um ganho genético de $2,8 \%$ para a ALT e no tamanho efetivo populacional $\left(N_{e}\right)$ de 15 indivíduos não parentes e não endogâmicos. A correlação genética entre os caracteres altura e DAP foi baixa e não significativa, sugerindo pequenas possibilidades de seleção indireta entre os caracteres.

Palavras-chave: herdabilidade; melhoramento genético; Pinus; seleção genética; variação genética.
\end{abstract}

\begin{abstract}
Pinus caribaea var. hondurensis is the most common species of the genus Pinus planted in tropical regions of Brazil, due its adaptation to soil and climate conditions, fast growth, good trunk form and quality of the wood. The species is mainly used for sawmill and pulp and paper industry. The aim of this study was to estimate genetic parameters for growth traits in a open-pollinated progeny test established in the Floresta Estadual de Assis, state of São Paulo. The test was implanted in May 1987, using a 4 x 5 triple lattice design with 17 treatments (16 progenies and a control), four replications and ten plants in row per plot, spaced $3 \times 3 \mathrm{~m}$. The total tree height -ALT and the diameter at breast height - DBH were measured at 21 years of age. The analysis of variance detected significant difference among progenies for tree height.
\end{abstract}

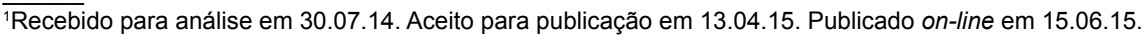

2Pós-Graduação em Agronomia, UNESP, Faculdade de Engenharia de llha Solteira, Avenida Brasil, 56, Centro, 15385-000 Ilha Solteira, SP, Brasil. ${ }^{3}$ Instituto Florestal, Rua do Horto, 931, 02377-000 São Paulo, SP, Brasil.

${ }^{4}$ Autor para correspondência: Miguel Luiz Menezes Freitas- miguellmfreitas@yahoo.com.br
} 
The coefficients of genetic variation were $18.4 \%$ for tree height and $9.2 \%$ for DBH. The estimates of heritability coefficient for progeny means were 0.30 for height and 0.02 for $\mathrm{DBH}$, higher than the estimates obtained at individual plant level and within progenies. To establish a seedling seed orchard, it is suggested to consider the trait height and a selection intensity of $6 \%$, which corresponds to the selection of the best 32 individuals. This procedure resulted a genetic gain of $2.8 \%$ for ALT and a population effective size $\left(N_{e}\right)$ of 15 unrelated and not inbred individuals. The genetic correlation between traits ALT and DBH was low and not significant, suggesting small chances of indirect selection between traits.

Keywords: genetic improvement; genetic variation; heritability; Pinus; genetic selection.

\section{INTRODUÇÃO}

O cultivo em larga escala de espécies de Pinus no Brasil ocorreu principalmente para suprir a necessidade de madeira para abastecimento industrial nas regiões Sul e Sudeste, diminuindo a supressão das áreas nativas. A opção de se utilizar o gênero Pinus ocorreu por suas espécies apresentarem boas características tecnológicas, rápido crescimento e boa adaptação às condições de clima e solo do Brasil (Freitas et al., 2005).

Segundo Lamprecht (1990), existem mais de 100 espécies pertencentes ao gênero Pinus. Uma delas é o Pinus caribaea, o qual se subdivide em três variedades: caribaea, hondurensis e bahamensis. O Pinus caribaea var. hondurensis tem zona de ocorrência natural na América Central, entre os paralelos $12^{\circ} 13^{\prime} \mathrm{N}$, na Nicarágua (Lamprecht, 1990).

Pinus caribaea var. hondurensis é uma das espécies do gênero mais plantadas no Brasil por apresentar ótima adaptabilidade às condições edafoclimáticas das regiões tropicais (Moraes et al., 2007; Tambarussi et al., 2010). A matéria-prima é principalmente utilizada para serraria e produção de celulose com grande aceitação comercial em todo o mundo (Lima, 1990). O sucesso comercial dessa variedade ocorre principalmente pela disponibilidade de sementes no mercado, ao seu bom desenvolvimento em solos pobres e à elevada qualidade de sua madeira, amplamente utilizada na construção civil (Moraes et al., 2007; Tambarussi et al., 2010).

Os estudos com o Pinus caribaea var. hondurensis vem revelando que esta variedade apresenta ampla variação genética entre e dentro de populações, e ótimo potencial para o melhoramento genético. A presença dessa variabilidade genética pode ser determinada a partir da estimativa do coeficiente de variação genética, que expressa a magnitude da variação genética da população em estudo (Vencovsky, 1987).

Os programas de melhoramento genético com Pinus caribaea var. hondurensis baseiam-se na seleção entre e dentro de progênies. Nesse esquema, identificam-se as melhores progênies com base nas médias das parcelas e depois as melhores árvores dentro das melhores progênies. Assumindo-se que progênies de polinização aberta são meios-irmãos, $25 \%$ da variação genética é do tipo aditiva, variação genética que é herdável e pode ser aproveitada na seleção entre progênies (Namkoong et al., 1966).

Para obter populações geneticamente melhoradas e que satisfaçam as exigências da produtividade florestal, o melhorista deve identificar os melhores indivíduos na população sob seleção. Uma estratégia de eficiência, comprovada para seleção desses genótipos, é o teste de progênies. Assim, o objetivo deste trabalho foi estimar a variação genética para os caracteres silviculturais em um teste de progênies de polinização aberta de Pinus caribaea var. hondurensis

\section{MATERIAL E MÉTODOS}

O teste de progênies foi instalado em maio de 1987, na Floresta Estadual de Assis, SP, situada a $22^{\circ} 35^{\prime} \mathrm{S}, 50^{\circ} 22^{\prime} \mathrm{W}$ e a uma altitude média de $562 \mathrm{~m}$. Segundo a classificação de Köppen, a região do estudo se encontra em uma zona de transição climática entre os tipos CWA e CFA. A precipitação média anual fica ao redor de $1.400 \mathrm{~mm}$ e a temperatura média anual é de $21,8^{\circ} \mathrm{C}$. O solo do local é caracterizado pela Empresa Brasileira de Pesquisa Agropecuária - EMBRAPA (1999) como Latossolo Vermelho Distrófico álico típico A moderado e textura média. 
O teste foi composto por 16 progênies de Pinus caribaea var. hondurensis e uma testemunha comercial. As matrizes (plantas-mães), que pertencem ao programa de melhoramento genético do Instituto Florestal, foram selecionadas principalmente para os caracteres volume, forma do fuste e produção de resina, e estão localizadas na Floresta Estadual de Assis. O delineamento experimental utilizado foi látice triplo $4 \times 5$, totalizando 17 tratamentos (16 progênies +1 testemunha comercial), com quatro repetições. Essa testemunha é considerada o tratamento comum, uma vez que está presente em todos os blocos. As parcelas foram compostas por dez plantas em linha no espaçamento de $3 \times 3 \mathrm{~m}$. A bordadura foi formada por três linhas. A coleta de dados foi realizada aos 21 anos de idade para diâmetro à altura do peito (DAP - 1,30 $\mathrm{m}$ acima do solo) e altura total das árvores. As variáveis foram tomadas por meio de suta graduada e hipsômetro de Blume-Leiss, respectivamente.

As análises de variância para os caracteres em estudo foram realizadas com o auxílio do programa SAS (Statistical Analysis System) (SAS, 1999).
Embora o delineamento experimental utilizado tenha sido o látice, as análises estatísticas foram feitas obedecendo ao modelo de blocos ao acaso, excluindo-se a testemunha. A expressão que representa o modelo matemático é a seguinte:

$$
Y_{i j k}=m+t_{i}+b_{j}+e_{i j}+d_{j k}
$$

em que: Yijk: performance média do $k$-ésimo indivíduo, do $j$-ésimo bloco, da $i$-ésima progênie; $m$ : média geral da variável em análise; $t_{i}$ : efeito da $i$-ésima progênie $(\mathrm{i}=1,2, \ldots, \mathrm{I}) ; b_{j}$ : efeito do $j$-ésimo bloco $(j=1,2, \ldots, J)$; $e_{i j}$ : efeito da interação entre a $i$-ésima progênie do $j$-ésimo bloco, ou efeito ambiental da $i j$-ésima parcela; $d_{i j k}$ : efeito do $k$-ésimo indivíduo dentro da $i j$-ésima parcela.

Com exceção do efeito de blocos, todos os demais efeitos do modelo foram assumidos como aleatórios, sendo que, $K$ é o número de árvores por progênies, $J$ é o número de blocos, $I$ é o número de progênies e $\bar{K}$ é a média harmônica do número de árvores por parcela. $\mathrm{O}$ esquema da análise de variância encontra-se na Tabela 1.

Tabela 1. Esperanças de Quadrados Médios para as variáveis em nível de plantas individuais para os caracteres DAP e altura de plantas.

Table 1. Expected mean squares for the variables in level of individual plants for the traits plant height and DBH.

\begin{tabular}{lclc}
\hline F.V. & GL & QM & E(QM) \\
\hline Blocos & $J-1$ & QMB & - \\
Progênies & $I-1$ & QMG & $\sigma_{d}^{2}+\bar{K} \sigma_{e}^{2}+J \bar{K} \sigma_{p}^{2}$ \\
Resíduo & $(J-1)(I-1)$ & QMR & $\sigma_{d}^{2}+\bar{K} \sigma_{e}^{2}$ \\
Dentro & $J I \sum(\bar{K}-1)$ & QMD & $\sigma_{d}^{2}$ \\
\hline
\end{tabular}

$J$ : número de blocos; $I$ : número de progênies; $K$ : número de plantas por progênies; p: é o número de parcelas; efeito de repetições; $\sigma_{e}^{2}$ : variância ambiental; $\sigma_{p}^{2}$ : variância genética entre progênies; $\sigma_{d}^{2}$ : variância fenotípica dentro de progênies. 
A análise de variância foi utilizada para estimar os componentes de variância, com base no método REML (Restricted Maximun Likelihood), em combinação com o comando VARCOMP do programa estatístico SAS, visto que o teste estava desbalanceado. Os componentes estimados foram: $\sigma_{p}^{2}$ : variância genética entre progênies; $\sigma_{e}^{2}$ : variância ambiental e $\sigma_{d}^{2}$ : variância fenotípica dentro de progênies. Desses componentes de variância foram estimadas a variância fenotípica total $\left(\sigma_{F}^{2}=\sigma_{d}^{2}+\sigma_{e}^{2}+\sigma_{p}^{2}\right)$ e variância genética aditiva, $\sigma_{A}^{2}=\sigma_{p}^{2} / r_{x y}$, sendo $r_{x y}$ o coeficiente médio de parentesco entre plantas dentro de progênies, assumido como 0,25 , ou seja, assumindo as plantas das progênies de polinização aberta como sendo meias-irmãs.

Os coeficientes de herdabilidade, o coeficiente de variação genética e medidas de correlações entre caracteres foram estimados com base em Namkoong (1979). Foram estimados os coeficientes de herdabilidade em nível de média de progênies $\left(h_{m}^{2}\right)$, dentro de progênies $\left(h_{d}^{2}\right)$, em nível de plantas individuais $\left(h_{i}^{2}\right)$, coeficiente de variação genética (CVg) e acurácia (Ac) utilizando-se as expressões:

$$
h_{m}^{2}=\frac{\sigma_{p}^{2}}{\sigma_{P}^{2}+\frac{\sigma_{e}^{2}}{J}+\frac{\sigma_{d}^{2}}{J K}}
$$

em que: $J$ é o número de repetições e $K$ é o número de plantas por parcela.

$$
\begin{gathered}
h_{d}^{2}=\frac{\left(1-r_{x y}\right) \sigma_{A}^{2}}{\sigma_{d}^{2}} \\
h_{i}^{2}=\frac{\sigma_{A}^{2}}{\sigma_{p}^{2}+\sigma_{e}^{2}+\sigma_{d}^{2}} \\
C V_{g}=\frac{\sqrt{\sigma_{p}^{2}}}{\hat{m}} \cdot 100
\end{gathered}
$$

$$
A C=\sqrt{h_{m}^{2}}
$$

sendo $m$ a estimativa da média do caráter.

Os ganhos genéticos esperados com a seleção foram calculados apenas dentro de progênies $\left(G_{d}\right)$, visto que o número de progênies era baixo (16). O ganho predito foi calculado por:

$$
G_{d}=i_{d} \sigma_{d} h_{d}^{2}
$$

em que, $i_{e}\left(\mathrm{i}_{\mathrm{d}}\right)$ é intensidade de seleção em unidade de desvio-padrão, aplicada dentro progênies e $\sigma_{d}$ é o desvio-padrão da variância fenotípica dentro de progênies. Neste estudo, adotou-se a intensidade de seleção de $6 \%$ entre plantas dentro de progênies para ambos os caracteres DAP e altura, o que estreita a base genética para os 32 melhores indivíduos. O ganho genético em percentagem $\left(G_{d}(\%)\right.$ foi calculado por:

$$
G_{d}(\%)=100\left(G_{d} / m\right)
$$

em que $m$ é a média do caractere sob seleção.

O tamanho efetivo $\left(N_{e}\right)$ foi calculado para a população após a seleção das duas melhores plantas das 16 progênies testadas. Assim, vão existir 16 pares de indivíduos parentes na população selecionada. Assumiu-se, ainda, que essas duas plantas de cada uma das 16 progênies eram parentes no grau de meios-irmãos. O tamanho efetivo total da população selecionada foi estimado seguindo Cockerham (1969) e utilizando-se a expressão:

$$
N_{e}=\frac{0,5}{\Theta \frac{n-1}{n} \quad \frac{1+F_{o}}{2 n}}
$$


em que $n$ é o número de plantas selecionadas (30), $F_{p}\left(\mathrm{~F}_{\mathrm{o}}\right)$ é o coeficiente de endogamia das progênies, assumido como zero, e $\Theta$ é o coeficiente de coancestria de grupo das 32 árvores selecionadas, o qual foi calculado pela seguinte expressão:

$$
\Theta=\frac{0,5 n\left(1+F_{p}\right)+\sum_{i=1}^{n} \sum_{i \neq j}^{n} \theta_{x y}}{n^{2}} \text { (Lindgren et al., 1996), }
$$

em que $n$ é o tamanho da população selecionada (30), $F_{p}$ é o coeficiente de endogamia na população parental, assumido como zero, $\theta_{x y}$ é o coeficiente de coancestria entre os indivíduos $x$ e $y$.

As correlações fenotípicas $\left(r_{f}\right)$ e genéticas $\left(r_{g}\right)$, entre os caracteres DAP e altura, foram estimadas a partir dos valores individuais de acordo com as seguintes expressões:

$$
\begin{gathered}
r_{f}=\frac{\sigma_{F_{x} F_{y}}}{\sqrt{\sigma_{F_{x}}^{2} \cdot \sigma_{F_{y}}^{2}}} \\
r_{f}=\frac{\sigma_{p_{x p y}}}{\sqrt{\sigma_{p x}^{2} \cdot \sigma_{p y}^{2}}}
\end{gathered}
$$

em que: $\sigma_{F X F Y}$ e $\sigma_{P X P Y}$ são os produtos cruzados fenotípicos e genéticos dos caracteres $x$ e $y$, estimados das análises de covariância, $\sigma_{F X}^{2}, \sigma_{P X}^{2}$, e $\sigma_{F Y}^{2}, \sigma_{P Y}^{2}$, são as variâncias fenotípicas e genéticas dos caracteres $x$ e $y$, respectivamente (Falconer, 1987).

\section{RESULTADOS E DISCUSSÃO}

A análise de variância revelou diferenças significativas a $5 \%$ de probabilidade entre blocos para a variável altura (Tabela 2). Foram encontradas diferenças significativas a $5 \%$ de probabilidade entre progênies para $\mathrm{o}$ caráter altura, o que indica que existe a possibilidade de melhoramento genético da população pela seleção entre progênies. O coeficiente de variação experimental foi de média magnitude $(17,5 \%)$ para o DAP e para altura de plantas $(10,9 \%)$, indicando precisão aceitável dos dados. Sebbenn et al. (2005), estudando a variação genética em espécie desse gênero, encontraram resultados semelhantes.

Tabela 2. Resultados da análise de variância, coeficiente de variação experimental $\left(\mathrm{CV}_{\text {exp }}(\%)\right)$ e média para os caracteres DAP e altura de plantas avaliadas em progênies de Pinus caribaea var. hondurensis aos 21 anos de idade.

Table 2. Results of analysis of variance, experimental coefficient of variation $\left(\mathrm{CV}_{\text {exp }}(\%)\right)$ and mean for DBH and height in 21-year old Pinus caribaea var. hondurensis.

\begin{tabular}{ccccc}
\hline & \multicolumn{2}{c}{ DAP } & \multicolumn{2}{c}{ ALT } \\
\cline { 2 - 5 } Estimativas & QM & $\mathrm{F}$ & 38,35 & $\mathrm{~F}$ \\
\hline Blocos & 0,34 & $0,01^{\mathrm{ns}}$ & 18,95 & $3,59^{*}$ \\
Progênies & 39,18 & $1,56^{\mathrm{ns}}$ & 15,36 & \\
Resíduo & 40,40 & & 10,90 & \\
$\mathrm{CV}_{\text {exp }}(\%)$ & 17,50 & & 21,4 & \\
Média & 28,70 & &
\end{tabular}

$(*) P<0,05$, ns $=$ não significativo. 
O coeficiente de variação genética para DAP foi estimado em $9,2 \%$, o que pode ser considerado como de média magnitude (Tabela 3). Esse resultado diverge do encontrado por Freitas et al. (2005), que estudando a variabilidade genética entre procedências de Pinus caribaea var. hondurensis aos 32 anos, em Bebedouro - SP, obtiveram coeficiente de variação genética de $0,31 \%$, considerado baixo para esse caráter. Para altura de plantas o coeficiente de variação genética foi de $18,4 \%$, indicando que a variação genética é substancial entre as progênies e há possibilidade de aumentar a média da população pela seleção entre progênies. Moraes et al. (2007), estudando o efeito do desbaste seletivo nas estimativas de parâmetros genéticos em um teste de progênies de Pinus caribaea Morelet var. hondurensis, aos 14 anos de idade, encontraram resultados inferiores aos aqui obtidos $\left(\mathrm{CV}_{\mathrm{g}}\right.$ de $5,44 \%$ para a altura de plantas).
Isso demonstra o alto potencial do material genético testado, no presente ensaio, para a seleção.

As estimativas dos coeficientes de herdabilidade média entre as progênies $\left(h_{m}^{2}\right)$ foram maiores do que as obtidas para herdabilidade em nível de plantas individuais $\left(h_{i}^{2}\right)$ e herdabilidade dentro da parcela $\left(h_{d}^{2}\right)$ (Tabela 3$)$. De acordo com Vencovsky e Barriga (1994), a herdabilidade em nível de média de progênies é superior às herdabilidades individuais e dentro de progênies, quando os efeitos ambientais da primeira são minimizados pelo número de repetições e de plantas por parcela. Portanto, a seleção é mais eficiente com base nas médias de progênies do que em nível de plantas individuais. Em suma, as herdabilidades indicam que a seleção será mais eficiente entre progênies do que dentro de progênies ou massal no experimento, devido ao maior controle genético do caráter.

Tabela 3. Estimativas dos coeficientes de herdabilidade em nível de plantas individuais no sentido restrito $\left(h_{i}^{2}\right)$, herdabilidades médias entre progênies $\left(h_{m}^{2}\right)$, herdabilidades dentro da parcela $\left(h_{d}^{2}\right)$, ganho genético esperado com a seleção dentro progênies $\left(G_{d}\right)$ e ganho genético esperado com a seleção dentro progênies $\left(G_{d}(\%)\right)$ para os caracteres diâmetro à altura do peito - (DAP) e altura total - (ALT) em progênies de polinização aberta de Pinus caribaea var. hondurensis, aos 21 anos de idade, em Assis-SP.

Table 3. Estimates of the heritability coefficients in individual level $\left(h_{i}^{2}\right)$, average among progenies $\left(h_{m}^{2}\right)$ and within progenies $\left(h_{d}^{2}\right)$, coefficient of genetic variation $\left(\mathrm{CV}_{\mathrm{g}}(\%)\right)$, expected genetic gain for selection within progenies $\left(G_{d}\right)$ and expected genetic gain in percentage for selection within progenies $\left(G_{d}(\%)\right)$ for diameter at breast height $-(\mathrm{DBH})$ and total height - (ALT), in open-pollinated progenies of Pinus caribaea var. hondurensis, at 21 year of age, in Assis-SP.

\begin{tabular}{ccc}
\hline & \multicolumn{2}{c}{ Caráter } \\
\cline { 2 - 3 } Parâmetros & DAP & ALT \\
\hline$h_{i}^{2}$ & 0,01 & 0,12 \\
$h_{m}^{2}$ & 0,02 & 0,30 \\
$h_{d}^{2}$ & 0,01 & 0,13 \\
$\mathrm{CV}_{\mathrm{g}}(\%)$ & 9,20 & 18,4 \\
$G_{d}$ & 0,01 & 0,13 \\
$G_{d}(\%)$ & 0,35 & $2,8 \%$ \\
\hline
\end{tabular}


Para o caráter altura, a herdabilidade média de progênies $\left(h_{m}^{2}\right)$ foi substancial $(0,30)$, o que indica que o caráter apresenta controle genético que pode ser explorado pela seleção entre progênies. No entanto, a herdabilidade para o caráter DAP foi de baixa magnitude, logo apresentou baixo controle genético. Uma explicação para isso é o fato de que o material testado é oriundo de material previamente selecionado em teste de progênies, o que reduziu a variação genética entre as progênies.

Os ganhos genéticos foram estimados apenas dentro de progênies, devido ao pequeno número de progênies utilizadas no teste (16 progênies), o que poderia reduzir muito o tamanho efetivo da população selecionada (Tabela 3). Os ganhos genéticos esperados com a seleção das duas melhores plantas de cada progênie foram baixos para ambos os caracteres (Tabela 4), embora maiores para altura total de plantas. A intensidade de seleção adotada dentro de progênies foi alta $(6 \%)$, estreitando a base genética para os 32 melhores indivíduos. A seleção proposta resultou em um coeficiente de coancestria para o grupo formado por essas 32 árvores de 0,0195. Embora aparentemente baixa, essa coancestria resultou no tamanho efetivo de 14, ou seja, as 32 plantas selecionadas correspondem a aproximadamente 15 indivíduos não parentes e não endogâmicos. Assim, vão existir parentes na população selecionada e, portanto, alelos idênticos por descendência entre parentes.
A seleção de mais de uma árvore da mesma progênie em 16 progênies indica que podem ocorrer cruzamentos entre parentes na população de recombinação, ou seja, no pomar de sementes por mudas resultantes deste teste de progênies. Como a endogamia em uma geração corresponde ao coeficiente de coancestria entre os pais, de acordo com a estimativa do coeficiente de coancestria de grupo das 32 árvores, sob cruzamentos aleatórios na população selecionada, a endogamia esperada nas sementes é de apenas $2 \%$.

Uma próxima etapa de melhoramento com este material deve considerar o uso de cruzamentos controlados para explorar a combinação específica de cruzamentos e/ou a inclusão de mais indivíduos selecionados em outros testes, visto que o tamanho efetivo da população selecionada é muito baixo (15).

Os coeficientes de correlação genética e fenotípica entre os caracteres altura total e DAP foram positivos, mas baixos e não significativos (Tabela 4). De acordo com Sampaio et al. (1999), a seleção, quando é realizada em variáveis com correlações positivas e de alta magnitude, espera alta resposta correlacionada. A correlação genética encontrada para os caracteres, por ser não significativamente diferente de zero, sugere poucas chances de obter-se ganhos indiretos em um dos caracteres, com a seleção direta no outro.

Tabela 4. Correlações genéticas $\left(r_{g}\right)$ e fenotípicas $\left(r_{f}\right)$ em progênies de Pinus caribaea var. hondurensis para caracteres diâmetro a altura do peito - (DAP) e altura total - (ALT) aos 21 anos de idade, em Assis-SP.

Table 4. Genetic $\left(r_{g}\right)$ and phenotipic correlations $\left(r_{f}\right)$ in progenies of 21-year old Pinus caribaea var. hondurensis for diameter at breast height $-(\mathrm{DBH})$ and total height $-(\mathrm{ALT})$.

\begin{tabular}{lcc}
\hline Caracteres & $r_{g}$ & $r_{f}$ \\
\hline DAP vs ALT & 0,41 & 0,06 \\
\hline
\end{tabular}

DAP: diâmetro a altura do peito, ALT: altura de plantas 


\section{CONCLUSÕES}

Existe variação genética entre as progênies de Pinus caribaea var. hondurensis para o caráter altura de plantas.

A estimativa do coeficiente de herdabilidade para o caráter altura de plantas foi maior do que para o DAP, condicionando maior possibilidade de melhoramento genético pela seleção.

A correlação genética entre os caracteres altura total e o DAP foi baixa, o que indica poucas chances do uso da seleção indireta entre estes caracteres.

\section{AGRADECIMENTOS}

Os autores são gratos aos funcionários do Instituto Florestal, Luis Carlos Malícia e Silvio dos Santos, pelo apoio à mensuração do experimento. Os autores Alexandre Magno Sebbenn e Miguel Luiz Menezes Freitas agradecem ao Conselho Nacional de Desenvolvimento Científico e Tecnológico - CNPq, pela concessão da bolsa de Produtividade em Pesquisa.

\section{REFERÊNCIAS BIBLIOGRAFICAS}

COCKERHAM, C.C. Variance of gene frequencies. Evolution, v. 23, p. 72-84, 1969.

EMPRESA BRASILEIRA DE PESQUISA AGROPECUÁRIA - EMBRAPA. Sistema brasileiro de classificação de solos. Brasília, DF, 1999. 412 p.

FALCONER, D.S. Introdução à genética quantitativa. Viçosa, MG: Universidade Federal de Viçosa, 1987. 279 p.

FREITAS, M.L.M. et al. Testes de procedências de Pinus caribaea var. hondurensis aos 32 anos de idade em Bebedouro-SP. Revista do Instituto Florestal, v. 17, n. 1, p. 17-23, 2005.

LAMPRECHT, H. Silvicultura nos trópicos: ecossistemas florestais e respectivas espécies arbóreas - possibilidades e métodos de aproveitamento sustentado. Eschborn: Universidade de Gottingen, Instituto de Silvicultura, 1990. 343 p.
LIMA, R.T. Comportamento de espécies e procedências tropicais do gênero Pinus em Felixlândia, MG, Brasil: região de cerrados. 1- Pinus caribaea var. hondurensis e Pinus oocarpa. Revista Árvore, v. 14, n. 1, p. 16-25, 1990.

LINDGREN, D.; GEA, L.; JEFFERSON, P. Loss of genetic diversity by status number. Silvae Genetica, v. 45, p. 52-59, 1996.

MORAES, M.L.T. et al. Efeito do desbaste seletivo nas estimativas de parâmetros genéticos em progênies de Pinus caribaea Morelet var. hondurensis. Scientia Forestalis, n. 74, p. 55-65, 2007.

NAMKOONG, G. Introduction to quantitative genetics in forestry. Washington, D.C.: Forest Service, 1979. 342 p. (Technical Bulletin No 1588).

; SNYDER, E.B.; STONECYPHER, R. Heritability and gain concepts for evaluating breeding systems such as seedling orchards. Silvae Genetica, v. 15, p. 76-84, 1966.

SAMPAIO, P.T.B.; RESENDE, M.D.V.; ARAÚJO, A.J. Estimativas de parâmetros genéticos e ganhos de seleção para o melhoramento genético de Pinus caribaea var. hondurensis. Pesquisa Agropecuária Brasileira, v. 35, n. 11, p. 2243-2253, 1999.

S.A.S. INSTITUTE INC. SAS procedures guide. Version 8 (TSMO). Cary, 1999. 454 p.

SEBBENN, A.M. et al. Variação genética em procedências e progênies de Pinus patula ssp. tecunumanii no noroeste do Estado de São Paulo. Revista do Instituto Florestal, v. 17, n. 1, p. 1-15, 2005.

TAMBARUSSI, E.V. et al Estimative of genetic parameters in progeny test of Pinus caribaea Morelet var. hondurensis Barret \& Golfari by quantitative traits and microsatellite markers. Bragantia, v. 69, p. 39-47, 2010. 
MACEDO, H.R. et al. Variabilidade genética em Pinus

VENCOVSKY, R. Tamanho efetivo populacional na coleta e preservação de germoplasmas de espécies alógamas. IPEF, v. 35, p. 79-84, 1987.

; BARRIGA, P. Genética biométrica no fitomelhoramento. São Paulo: Sociedade Brasileira de Genética, 1994. 496 p. 